\begin{tabular}{l|l} 
Jurnal & ISSN 2615-3939 \\
& IAIN Kudus \\
hendidik://journal.stainkudus.ac.id/index.php/jmtk \\
Matematika
\end{tabular}

\title{
EKSPERIMENTASI MODEL PEMBELAJARAN KOOPERATIF TIPE THREE STEPS INTERVIEW(TSI) DENGAN PENDEKATAN SAINTIFIK PADAMATERI FUNGSI DITINJAU DARIKECERDASAN MATEMATIS LOGISSISWA
}

\author{
Rizqona Maharani \\ rmaharani@stainkudus.ac.id \\ Program Studi Tadris Matematika, Fakultas Tarbiyah, IAIN Kudus \\ J1. Conge Ngembal Rejo No. 51 Kudus-Jawa Tengah
}

\begin{abstract}
Abstrak
Penelitian ini bertujuan untuk mengetahui pengaruh model pembelajaran kooperatif tipe Three Steps Interview (TSI) dengan Pendekatan Saintifik (PS) dan Pembelajaran Klasikal dengan Pendekatan Saintifik (PS)terhadap prestasi belajar matematika ditinjau dari kecerdasan multiple.Penelitian ini merupakan eksperimental semu dengan desain faktorial $2 \times 3$ danpopulasinya adalah seluruh siswa kelas 8 di SMPN Sukoharjo.Pengumpulan data digunakan instrumen tes prestasi belajar matematika dan angket kecerdasan matematis logis. Teknik analisis data menggunakan uji ANAVA dua jalan dengan sel tak sama. Hasil penelitian ini adalah (1)Siswa yang dikenai model TSI-PS memperoleh prestasi belajar lebih baik daripada siswa yang dikenai model Klasikal-PS. (2)Siswa yang memiliki kecerdasan matematis logis tinggi memperoleh prestasi belajar lebih baik dibanding siswa dengan kecerdasan matematis logis sedang dan rendah, siswa dengan kecerdasan matematis logis sedang memperoleh prestasi belajar lebih baik daripada siswa dengan kecerdasan matematis logis rendah (3)Pada setiap model pembelajaran, siswa dengan kecerdasan matematis logis tinggi memperoleh prestasi belajar lebih baik dibanding siswa dengan kecerdasan matematis logis sedang dan rendah, siswa dengan kecerdasan matematis logis sedang memperoleh prestasi belajar lebih baik daripada siswa dengan kecerdasan matematis logis rendah(4)Pada setiap tingkat kecerdasan matematis logis, siswa yang dikenai model TSI-PS memperoleh prestasi belajar lebih baik daripada siswa yang dikenai model Klasikal-PS.
\end{abstract}

Kata Kunci: Three StepsInterview(TSI), Pembelajaran Klasikal, Pendekatan Saintifik (PS), Kecerdasan Matematis Logis.

\footnotetext{
Abstract:

The purpose of this study was to determine the effect of the learning models of cooperative learning of the three steps interview (TSI) type with scientific approach, and classical learning with scientific approach on the learning
} 
achievement in mathematics viewed from the students' logical mathematical intelligence. The study type was quasi experimental with a $2 \times 3$ factorial design. The population was all grade 8 students of Secondary Schools in Sukoharjo. Instruments used for data collection were mathematics achievement test and logical mathematical intelligencequestionnaire. The data analysis technique used was the two-way ANOVA with unequal cell. The results of the study could be concluded as follows. (1)TSI with scientific approach got better learning achievement than classical with scientific approach. (2) Students with high logical mathematical intelligence got better achievement than students with moderat and low logical mathematical intelligence and students with moderat logical mathematical intelligence got better achievement than students with low logical mathematical intelligence. (3) Viewed from learning models, Students with high logical mathematical intelligence got better achievement than students with moderat and low logical mathematical intelligence and students with moderat logical mathematical intelligence got better achievement than students with low logical mathematical intelligence. (4)Viewed logical mathematical intelligence categories, TSI with scientific approach got better learning achievement than classical with scientific approach

Kata Kunci: Three Steps Interview (TSI), Classical Learning, Scientific Approach, logical mathematical intelligence.

\section{PENDAHULUAN}

Matematika merupakan salah satu mata pelajaran di sekolah yang memiliki peranan penting dalam keberhasilan pembangunan mutu pendidikan di Indonesia. Matematika dianggap sebagai ilmu dasar (basic science) yang berfungsi sebagai alat bantu, pembimbing pola pikir, maupun sebagai pembentuk sikap. Pada pembelajaran matematika terdapat kegiatan berpikir untuk mengkaji sesuatu secara logis dan sistematis.Selain itu, matematika merupakan ilmu yang bersifat deduktif dan materinya bersifat abstrak.Hal ini sejalan dengan pendapat Hudoyo (1988, p.3) bahwa matematika berkaitan dengan ide-ide (gagasan-gagasan), struktur-struktur dan hubungan-hubungan yang diatur secara logis, sehingga matematika itu berkaitan dengan konsep-konsep yang abstrak.Matematika juga memiliki nilai kebenaran yang dikembangkan berdasarkan alasan logis dengan menggunakan pembuktian secara deduktif.

Tidak heran jika beberapa siswa masih mengalami kesulitan dalam memahami materi matematika yang bersifat abstrak tersebut, bahkan merasa tidak mampu dalam merumuskan masalah/ problem posing pada pembelajaran matematika.Padahal merumuskan masalah merupakan hal dasar yang sering dilakukan di berbagai kegiatan matematis dan merupakan suatu komponen penting dalam menyelesaikan masalah. Hal 
ini sesuai dengan pendapat Brown dan Walter dalam Johnson (2000, p.30), "problem posing is an important component of problem solving and is fundamental to any mathematical activity". Tidak hanya itu saja, pada materi matematika yang tergolong mudah sekalipun, siswa masih merasa tidak mampu untuk merumuskan masalahnya, seperti materi fungsi. Fungsi merupakan salah satu materi matematika kelas VIII SMP/MTS yang termasuk dalam materi aljabar, adalah materi prasyarat yang mudah untuk dipahami karena bersifat esensial dan prosedural (Maharani dkk, 2016, p.853).

Johnson (2000, p.26-29) menunjukkan beberapa kesulitan yang dialami siswa yaitu, kesulitan siswa dalam menyederhanakan dan menjabarkan persamaan aljabar, sehingga siswa menghasilkan persamaan yang salah seperti $a+(b x c)=(a+b) x(a+c)$, $\sqrt{a+b}=\sqrt{a}+\sqrt{b}$, dan $(a+b)^{2}=a^{2}+b^{2}$.Siswa juga mengalami kesulitan dalam menyajikan dan menyelesaikan persoalan aljabar dalam soal cerita. Selain itu, siswa masih bermasalah dengan istilah-istilah dalam materi fungsi seperti kodomain, domain, daerah hasil, fungsi satu-satu, dan onto, yang kemudian mempengaruhi kemampuannya dalam menyajikan grafik fungsi. Hal ini dipertegas oleh Maharani dkk ( 2016, p.2) yang menunjukkan bahwa, sebagian besar siswa SMP di Kota Sukoharjo masih mengalami kesulitan dalam menyelesaikan soal-soal yang berkaitan dengan materi relasi dan fungsi.

Oleh karenanya, sebagai seorang guru hendaknya mampu mengidentifikasi faktor penyebab kesulitan siswa pada pembelajaran matematika sehingga diperoleh solusi yang tepat. Adapun hal penting yang perlu dikaji adalah proses pembelajaran matematika di kelas. Saat kegiatan belajar mengajar matematika berlangsung, beberapa siswa terlihat kurang berani untuk bertanya dan mengungkapkan pendapat yang dimiliki, mereka juga kurang mampu mengaitkan pengetahuan yang telah dimiliki dengan pengetahuan baru yang akan dipelajari, serta belum terbiasa untuk mengubah bentuk permasalahan sehari-hari ke dalam simbol-simbol matematika (Anggraheni, 2013,p.2). Selain itu, guru di kelas lebih sering menyampaikan materi dan hanya berfokus pada keterselesaian bahan ajar saja. Akibatnya, tidak semua siswa terlayani kebutuhan belajarnya. Model pembelajaran yang diterapkan guru tersebut adalah model pembelajara klasikal.

Selain itu, faktor lain yang mempengaruhi keberhasilan siswa adalah kecerdasan yang dimilikinya yang mempengaruhi kecepatan dan ketepatan dalam memahami 
materi matematika. Setiap siswa memiliki kecepatan yang berbeda-beda dalam memahami matematika. Hal ini disebabkan oleh level kecerdasan yang dimiliki setiap siswa juga berbeda-beda. Gardner berpendapat bahwa setidaknya ada delapan jenis kecerdasan dasar yang menentukan keberhasilan seseorang. Kecerdasan tersebut adalah kecerdasan linguistic, logical-mathematical, visual-spatial, bodily-kinesthetic, interpersonal, intrapersonal, dan naturalis(Amstrong, 2013, p.5). Akan tetapi, kecerdasan yang dianggap sangat mempengaruhi keberhasilan siswa pada pembelajaran matematika adalah kecerdasan matematis logis/ logical-mathematical.Hal ini sejalan dengan Huri (2012) yang menunjukkan bahwa, kecerdasan matematis logis memiliki pengaruh yang signifikan dengan hasil belajar matematika. Selain itu, Igan (2013) menunjukkan adanya kontribusi langsung kecerdasan matematis logis terhadap prestasi belajar matematika sebesar $62,6 \%$. Ini artinya kecerdasan matematis logis merupakan faktor internal yang mempengaruhi prestasi belajar matematika siswa.

Adapun klasifikasi kemampuan pada kecerdasan matematis logis adalah kemampuan menganalisis masalah-masalah logis, menyelesaikan operasi matematika, dan menyelidiki isu yang bersifat ilmiah (Abdulkarim dan Al jadiry, 2012,p.141). Kemampuan-kemampuan tersebut merupakan faktor yang menentukan kadar kecerdasan matematis logis dan dapat dikembangkan dengan cara yang berbeda-beda pada setiap individu.Cara yang dapat dilakukan adalah dengan merancang kegiatan pembelajaran sesuai yang dapat melibatkan dan mengakomodasi kecerdasan matematis logis siswa (Amstrong, 2013, p.61). Abdulkarim dan Al Jadiry (2012) menyatakan bahwa terdapat hubungan signifikan antara pembagian kelompok pada pembelajaran kooperatif berdasarkan teori kecerdasan multiple, termasuk kecerdasan matematis logis. Ini berarti bahwa pembelajaran kooperatif memuat kegiatan pembelajaran yang dapat mengembangkan dan mengakomodasi kecerdasan matematis logis siswa.

Pembelajaran kooperatif adalah salah satu inovasi pembelajaran yang membuat siswa belajar lebih aktif, berfikir lebih kritis, dan mampu berinteraksi dengan siswa yang lainnya serta mampu mengembangkan kecerdasan yang dimilikinya. Liang (2002, p.6) menyatakan bahwa,

"cooperative learning is defined as a system of concrete teaching and learning techniques, rather than an approach, in which students are active agents in the process of learning through small groups structures so that students work together to maximize their own and each other's learning”. 
Dari pendapat tersebut dapat diketahui bahwa pembelajaran kooperatif adalah suatu sistem teknik pengajaran dan pembelajaran yang konkret, daripada pendekatan, di mana siswa adalah agen aktif dalam proses pembelajaran melalui struktur kelompok kecil sehingga siswa bekerja sama untuk memaksimalkan pembelajaran mereka sendiri dan satu sama lainnya. Farzaneh dan Nejadesari (2014, p.288) menyatakan bahwa pembelajaran kooperatif adalah suatu model pembelajaran di mana pembelajar dengan kemampuan, bakat, dan latar belakang yang berebeda-beda bekerja sama dalam kelompok-kelompok kecil untuk mencapai tujuan bersama. Selain itu, Johnson dan johnson (2000, p.1) bahwa,

" cooperative learning is defined as a relationship in a group of students that requires positive interdependence (a sense of sink or swim together), individual accountibility (each of us has to contribute and learn), interpersonal skills (communication, trust, leadership, decision making, and conflict resolution), face to face promoting interaction, and processing (reflecting how well the team is functioning and how to function even better)".

Model pembelajaran kooperatif dirancang dan diterapkan untuk mengembangkan strategi sosial dan sikap sosial siswa, dan untuk meningkatkan hubungan sosial baik di dalam kelompok maupun antar kelompok. Sebagai tambahan, sebagian besar tujuan model pembelajaran kooperatif adalah pada pengembangan kognitif seperti pada pelajaran matematika. Terkadang model pembelajaran kooperatif juga diarahkan di antara pengembangan manusia dari segi sosial maupun segi kognitif (Terwel, 2011, p.1).

Sementara itu, Zakaria et al. (2010) menunjukkan bahwa pembelajaran kooperatif dapat meningkatkan prestasi belajar siswa pada mata pelajaran matematika.Bahkan Robertson dalam Sharan (1994) menyatakan bahwa, untuk memulai menggunakan pembelajaran kooperatif pada pembelajaran matematika di SMP, guru dapat memulai dengan beberapa model kooperatif yang sederhana yang dapat mendorong timbal balik siswa. Salah satu model pembelajaran kooperatif yang dapat diterapkan adalah model Three Steps Interview (TSI).

Model pembelajaran kooperatif TSI atau disebut juga dengan Three ProblemSolving merupakan model pembelajaran yang efektif digunakan untuk memecahkan masalah (problem solving). Sejalan dengan UNT (2008, p.4) menyatakan bahwa, Three step interview merupakan suatu model yang efektif digunakan saat siswa-siswa sedang memecahkan masalah (problem solving). Model ini dapat digunakan sebagai 
pengakraban untuk setiap anggota kelompok agar saling mengenal satu sama lain dan kegunaan lainnya termuat dalam Arra et al. (2011,p.115) bahwa, "three step interview can be used as a strategy to explore concepts in depth through student roles". Artinya Three step interview (TSI) dapat digunakan sebagai suatu cara untuk mengeksplorasi konsep secara mendalam melalui peran siswa. Selain itu, tujuan pada pengembangan akademik dan sosial siswa pada model ini meliputi partisipasi (participation), mendengarkan (listening), sosialisasi interaksi antara pembelajar (teambuilding), berpikir (thinking), komunikasi (communication), dan saling membagi informasi (Kagan dan Kagan, 1998, p.12).

Selain itu, Kagan (1990, p.15) menyatakan bahwa,

"three step interview but not the Co-op Cards is most often used for divergent thingking (evaluation, analysis, synthesis, and application level thinking), such as when the academic goal is promoting thought as part of participation in the scientific inquiry process or as part of writing process. Three step interview promotes listening skills and serves well to provide an anticipatory set for the lesson”.

Dari pernyataan tersebut dapat diketahui bahwa TSI sering ditujukan untuk berpikir divergen (tingkat pemikiran aplikasi, sintesis, analisis, dan evaluasi), seperti halnya pembelajaran yang bertujuan untuk meningkatkan pemikiran selama berpartisipasi dalam proses penemuan ilmiah atau selama kegiatan menulis. TSI juga dapat meningkatkan keterampilan dalam mendengarkan dan berfungsi dengan baik dalam menyiapkan serangkaian persiapan pelajaran.Model TSI ini memiliki tiga tahapan inti dalam menyelesaikan masalah. Selain itu, pada model ini siswa dituntut untuk menggunakan kemampuan kognitif pada tingkat berfikir aplikasi, analisis, sintesis, dan evaluasi. Pada model pembelajaran TSI, siswa melakukan kegiatan tanya jawab secara berpasangan. Pertama satu arah, kemudian mereka bertukar peran sebagai penanya dan penjawab. Siswa juga dapat bertukar informasi dengan penanya tentang apa yang telah mereka pelajari (Liang, 2002). Model ini mengandalkan kerja sama antar siswa dan terdapat tanggung jawab perseorangan. Selain itu, model ini menempatkan siswa dalam kelompok belajar yang beranggotakan empat orang dengan kemampuan yang berbedabeda.

Jika model pembelajaran TSI dikombinasikan dengan pendekatan saintifik maka terdapat kegiatan dalam proses penemuan ilmiah akan menjadi lebih menonjol diantaranya adalah kegiatan menanya, mengumpulkan informasi, menalar, dan 
mengkomunikasikan. Sementara untuk kegiatan mengamati, akan diinstruksikan oleh guru saat memberikan gambaran sekilas tentang materi yang berkaitan. The National Center on Quality Teaching and Learning (2012, p.1) menyatakan bahwa metode saintifik adalah suatu rangkaian langkah-langkah yang digunakan untuk membantu anak lebih baik dalam memahami dunianya.Sedangkan Betz (2011, p.21) mengemukakan bahwa"scientific method is a methodological approach to theprocess of inquiry - in which empirically grounded theory of nature is constructedand verified", artinya metode saintifik adalah suatu pendekatan metodologis untuk kegiatan peneyelidikandimana mengandaskan secara empiris pada teori alam dengan membangun dan membuktikan.

Guru-guru memasukkan metode saintifik ke dalam kegiatan-kegiatan saat mereka mendorong anak untuk bertanya, mengamati, memprediksi, mencoba, dan berdiskusi.Maharani (2015, p.116) menunjukkan bahwa model pembelajaran TSI dengan pendekatan saintifik memberikan prestasi belajar matematika siswa yang lebih baik daripada model pembelajaran klasikal dengan pendekatan saintifik. Berdasarkan implementasi kurikulum 2013 yang berbasis pada pendekatan saintifik maka dalam penelitian ini telah menerapkan model pembelajaran TSI yang dikombinasikan dengan pendekatan saintifik. Ini artinya, proses pembelajaran pada penelitian ini harus memuat lima komponen kegiatan yaitu mengamati, menanya, mengumpulkan informasi,menalar, dan mengkomunikasikan. Adapun langkah-langkah model pembelajaran TSI dengan menggunakan pendekatan saintifik dapat dilihat pada Tabel 1 berikut.

Tabel 2.2 Langkah-langkah Model TSI dengan Pendekatan Saintifik

\begin{tabular}{|l|c|}
\hline \multicolumn{1}{|c|}{ Kegiatan Pembelajaran Model TSI } & Pendekatan Saintifik \\
\hline a. Langkah Pembagian Kelompok: & \\
1) & $\begin{array}{l}\text { Guru memberikan gambaran sekilas mengenai materi yang akan } \\
\text { dipelajari dengan melibatkan siswa secara langsung untuk } \\
\text { mengamati objek yang ada di sekitarnya }\end{array}$ \\
2) Siswa dibagi menjadi beberapa kelompok dan setiap kelompok & mengamati \\
terdiri dari empat siswa (A, B, C, dan D) & \\
3) Siswa diberikan LKS untuk didiskusikan dan membagi soal \\
kepada setiap anggota sebagai tanggung jawab individu \\
b. Langkah kedua Tanya Jawab dan Bertukar Peran: \\
1) Siswa berdiskusi secara berpasangan dan berperan sebagai penanya \\
dan penjawab dalam memecahkan masalah. Setelah waktu yang \\
diberikan selesai, selanjutnya pasangan akan bertukar peran. \\
2) Siswa untuk memahami dan meresum penjelasan dari pasangannya \\
masing-masing \\
3) Setiap pasangan dalam kelompok berdisikusi dan saling
\end{tabular}


\begin{tabular}{|l|l|}
\hline menyampaikan dan menanggapi informasi yang diperoleh dari & \\
pasangannya & mengkomunikasikan \\
c. Langkah ketiga (Sharing) : & \\
1) Siswa menyampaikan informasi yang diperoleh dari setiap & \\
pasangannya di depan kelas kemudian kelompok lainnya saling & \\
menanggapi. & mengkomunikasikan \\
2) Guru melibatkan siswa secara aktif untuk menarik kesimpulan \\
pembelajaran yang telah didiskusikan bersama. & \\
3) Siswa diberikan evaluasi &
\end{tabular} Sedangkan model pembelajaran klasikal yang dikombinasikan dengan pendekatan saintifik. Ini artinya, proses pembelajaran pada penelitian ini harus memuat lima komponen kegiatan yaitu mengamati, menanya, menalar, mencoba, dan mengkomunikasikan. Berikut adalah langkah-langkah model pembelajaran klasikal yang dikombinasikan dengan pendekatan saintifik.

a. Guru menyajikan materi fungsi secara tahap demi tahap.

b. Siswa diberikanpermasalahan kontekstual yang ada di sekitar siswa dan siswa mengamati serta mencermati permasalahan kontekstual yang diberikan. (mengamati).

c. Dari kegiatan mengamati permasalahan yang diberikan, siswasecara individu diberikan kesempatan untuk bertanya (menanya)

d. Siswa secara individu diberikanLKS dan dituntun agar memperoleh ide-ide atau gagasan untuk menyelesaikan masalah yang diberikan.(mengumpulkan informasi)

e. Setiap siswa diminta untuk menerapkan gagasan yang telah diperoleh untuk mencoba menyelesaikan permasalahan yang telah diberikan.(menalar)

f. Beberapa siswa maju ke depan kelas untuk memaparkan jawabannya dan siswa lain menanggapinya untuk kemudian dapat ditarik kesimpulan bersama.

\section{(mengkomunikasikan).}

g. Siswa diberikan tugas sebagai pekerjaan rumah.

Adapun tujuan dari penelitian ini adalah untuk mengetahui: (1) prestasi belajar siswa yang lebih baik, di antara siswa yang dikenaimodel pembelajaran TSI-PS, atau pembelajaran Klasikal-PS pada materi fungsi, (2) prestasi belajar siswa yang lebih baik, di antara siswa yang memilikikecerdasan matematis-logis tinggi, sedang, atau rendah, (3) pada masing-masing kategori kecerdasan matematis logis, manakah yang memberikan prestasi belajar lebih baik di antara siswa yang dikenai pembelajaran dengan model pembelajaran kooperatif tipe TSI-PS atau pembelajaran Klasikal-PS pada materi fungsi. 


\section{METODE PENELITIAN}

Penelitian ini termasuk penelitian eksperimental semu yang dirancang dengan desain faktorial $2 \times 3$. Populasi pada penelitian ini adalah seluruh siswa SMPN kelas VIII di Kabupaten Sukoharjo tahun ajaran 2014/2015. Sampel diambil dengan teknik stratified cluster random sampling karena dari suatu sekolah yang dipilih secara acak, dipilih lagi secara acak dua kelas yang akan diperlakukan sebagai kelas eksperimen dan kelas kontrol. Kelas eksperimen yaitu kelas yang diberi perlakuan pembelajaran dengan model TSI dengan pendekatan saintifik, dan kelas kontrol yaitu kelas yang dikenai pembelajaran klasikal dengan pendekatan saintifik. Banyaknya sampel pada penelitian ini adalah 174 siswa yang mencakup 87 siswa pada kelas eksperimen dan 87 siswa pada kelas kontrol.

Pada penelitian ini terdapat dua variabela bebas yaitu model pembelajaran dan kecerdasan matematis logis. Sedangkan variabel terikatnya adalah hasil belajar siswa pada materi fungsi. Pengumpulan data menggunakan metode dokumentasi, tes, dan angket. Metode dokumentasi digunakan untuk mengumpulkan data berupa nilai pada aspek pengetahuan untuk mengetahui kemampuan awal siswa. Metode tes digunakan untuk mengumpulkan data pada aspek pengetahuan, sedangkan metode angket untuk memperoleh data tentang kecerdasan matematis logis siswa.

Penelitian ini menggunakan dua variabel bebas yaitu model pembelajaran dan kecerdasan matematis logissiswa, dan satu variabel terikat yaitu prestasi belajar matematika. Teknik pengumpulan data menggunakan metode dokumentasi, tes, dan angket. Metode dokumentasi digunakan untuk mengumpulkan data kemampuan awal siswa, metode tes digunakan untuk data prestasi belajar matematika siswa, dan metode angket digunakan untuk mengetahui data kategori multiple intelligences siswa. Instrumen tes yang digunakan dalam penelitian ini berbentuk tes objektif, dan instrumen angket yang digunakan adalah angket langsung dengan bentuk skala. Selanjutnya, uji prasyarat analisis pada penelitian ini menggunakan uji normalitas dengan Lilliefors dan uji homogenitas dengan uji Bartlett, sedangkan uji hipotesisnya menggunakan uji anava 
dua jalan dengan sel tak sama dan dilanjutkanuji komparasi ganda dengan metode Scheffe' jika hipotesis nol ditolak (Budiyono, 2013,p.170-217).

\section{HASIL PENELITIAN DAN PEMBAHASAN}

Hasil uji keseimbangan terhadap data kemampuan awal siswa diperoleh bahwa populasi memiliki kemampuan awal yang sama. Setelah eksperimen, diperoleh data prestasi belajar matematika yang kemudian dilakukan uji analisis variansi dua jalan dengan sel tak sama. Sebelum dilakukan uji tersebut, dilakukan terlebih dahulu uji normalitas dan uji homogenitas terhadap data tes prestasi belajar matematika yang telah diperoleh.

Setelah dilakukan uji normalitas dan uji homogenitas, dilakukan uji analisis variansi dua jalan dengan sel tak sama. Tabel 1 adalah hasil uji analisis variansi dua jalan dengan sel tak sama.

Tabel 1. HasilUji Analisis Variansi Dua Jalan dengan Sel Tak Sama

\begin{tabular}{|c|c|c|c|c|c|c|}
\hline Sumber & $J K$ & $D k$ & $R K$ & $F_{\text {obs }}$ & $F_{\alpha}$ & Keputusan \\
\hline $\begin{array}{c}\text { Model } \\
\text { Pembelajaran }(A)\end{array}$ & 2232,5262 & 1 & 2232,5262 & 8,4 & 3,84 & $H_{0 A}$ ditolak \\
\hline $\begin{array}{c}\text { Keccerdasan Mat } \\
\operatorname{Logis}(B)\end{array}$ & 13117,6602 & 2 & 6558,83 & 24,675 & 3 & $H_{0 B}$ ditolak \\
\hline Interaksi $(A B)$ & 197,9715 & 2 & 98,9857 & 0,37 & 3 & $H_{0 A B}$ diterima \\
\hline Galat & 44655,66 & 168 & 265,8075 & - & - & \\
\hline Total & 60203,8178 & 173 & - & - & - & \\
\hline
\end{tabular}

Berdasarkan Tabel 1 diperoleh bahwa (1) ada perbedaan prestasi belajar matematikadiantara siswa yang dikenai model pembelajaran TSI dengan Pendekatan Saintifik (TSI-PS), dan Klasikal dengan Pendekatan Saintifik (Klasikal-PS), (2) ada perbedaan prestasi belajar matematikadi antara siswayang memiliki kecerdasan matematis logis tinggi, sedang, dan rendah (3) tidak terdapat interaksi antara model pembelajaran dan kecerdasan matematis logissiswa terhadap prestasi belajar matematika.

Oleh karena pada uji analisis variansi dua jalan dengan sel tak sama diperoleh keputusan $H_{0 A}$ ditolak dan $H_{0 B}$ ditolak maka dilakukan uji komparasi ganda. Uji komparasi ganda yang dilakukan hanya uji komparasi ganda antar kolom (kecerdasan matematis logis).Uji komparasi ganda antar baris tidak perlu dilakukan karena untuk 
melihat mana yang lebih baik antara TSI-PS dan klasikal-PS langsung bisa melihat reratanya.Sedangkan untuk hasil yang menunjukan bahwa $H_{0 A B}$ diterima, tidak perlu dilakukan uji komparasi ganda. Untuk keperluan uji komparasi ganda, berikut ini disajikan rangkuman data rerata sel dan rerata marginal pada Tabel 2.

Tabel 2. Rangkuman Data Rerata Sel dan Rerata Marginal

\begin{tabular}{ccccc}
\hline Model & \multicolumn{3}{c}{ Kecerdasan matematis logis $(\boldsymbol{B})$} & \multirow{2}{*}{ Rerata Marginal } \\
\cline { 2 - 4 } $\begin{array}{c}\text { Pembelajaran } \\
(\boldsymbol{A})\end{array}$ & Tinggi & Sedang & Rendah & \\
\hline TSI-PS & 87,5294 & 70,3704 & 62 & 72,1839 \\
Klasik-PS & 77 & 65,4035 & 51,7778 & 64,1839 \\
\hline Rerata Marginal & 83,1724 & 67,8198 & 56,5882 & - \\
\hline
\end{tabular}

Berdasarkan keputusan uji anava, dan data rerata marginal maka ditunjukkan bahwa rata-rata nilaisiswa yang dikenai model pembelajaran kooperatif tipe TSI-PS lebih besar daripada rata-rata siswa yang dikenai model Klasikal-PS. Akibatnya, siswa yang dikenai model pembelajaran kooperatif tipe TSI-PSmemiliki prestasi belajar lebih baik daripadasiswa yang dikenai model Klasikal-PS. Hasil tersebut sesuai dengan hasil penelitian yang ditunjukkan Atsnan dan Rahmita (2013) bahwa, pembelajaran berbasis pendekatan saintifik lebih efektif hasilnya dibandingkan dengan pembelajaran tradisional.Hasil penelitian Azmir et al. (2011) menunjukkan bahwa penerapan model pembelajaran kooperatif lebih baik dibandingkan pembelajaran klasikal dalam membantu memahami materi. Hal ini sejalan dengan hasil penelitian yang diperolehAwofala et al. (2012) bahwa, strategi kooperatif lebih efektif dalam kegiatan belajar mengajar pada siswa SMP, dan mampu meningkatkan penguasaan kemampuan berpikir pada tingkat pemahaman dan aplikasi daripada pada tingkat pengetahuan saja.

Berdasarkan hasil perhitungan pada uji komparasi ganda antar kolom, diperoleh hasil $F_{.1-.2}=20,3887$ pada pembandingan kolom kesatu dan kolom kedua, pembandingan kolom kesatu dan ketiga diperoleh $F_{.1-.3}=41,611$ dan pembandingan kolom kedua dan ketiga diperoleh $F_{.2-.3}=12,3524$ dengan $\mathrm{DK}=\{\mathrm{F} \mid \mathrm{F}>6\}$. Oleh karena $F_{.1-.2} \in D K, F_{.1-.3} \in D K$, dan $F_{.2-.3} \in D K$ maka memiliki keputusan uji $H_{0}$ ditolak. Melihat pada keputusan uji anava, uji komparasi ganda antar kolom, dan data rerata marginal makadapat diketahui bahwa siswa yang memiliki kecerdasan matematis logis tinggi memperoleh prestasi belajar yang lebih baik dibandingkan dengan siswa yang memiliki kecerdasan matematis logis sedang,dan siswa dengan kecerdasan 
matematis logis tinggi memperoleh prestasi belajar lebih baik daripada siswa yang memiliki kecerdasan rendah,serta siswa dengan kecerdasan matematis logissedang memperoleh prestasi belajar lebih baik daripada siswa dengan kecerdasan kecerdasan matematis logisrendah.

Berdasarkan hasil perhitungan uji anava dua jalan dengan sel tak sama pada interaksi antara kategori model pembelajarandan kecerdasan matematis logissiswa terhadap prestasi belajar matematika siswa $(A B)$ diketahui $H_{O A B}$ diterima, sehingga kesimpulan mengikuti atau sama dengan kesimpulan pada efek utama antar kolom dan baris.Hasil pada penelitian ini menujukkan bahwa siswa yang dikenai model pembelajaran (TSI-PS) memiliki prestasi belajar yang lebih baik daripada siswa yang dikenai model pembelajaran(Klasikal-PS), siswa yang memiliki kecerdasan matematis logis tinggi memperoleh prestasi belajar yang lebih baik dibandingkan dengan siswa yang memiliki kecerdasan matematis logis sedang,dan siswa dengan kecerdasan matematis logis tinggi memperoleh prestasi belajar lebih baik daripada siswa yang memiliki kecerdasan rendah,serta siswa dengan kecerdasan matematis logissedang memperoleh prestasi belajar lebih baik daripada siswa dengan kecerdasan kecerdasan matematis logisrendah.

\section{KESIMPULAN DAN SARAN}

Berdasarkan hasil analisis data dan pembahasan yang telah dilakukan maka dapat disimpulkan hasil penelitian sebagai berikut. (1) Siswa yang dikenai model TSI dengan pendekatan saintifik memperoleh prestasi belajar lebih baik daripadasiswa yang dikenai model Klasikal dengan pendekatan saintifik. (2) siswa yang memiliki kecerdasan matematis logis tinggi memperoleh prestasi belajar yang lebih baik dibandingkan dengan siswa yang memiliki kecerdasan matematis logis sedang,dan siswa dengan kecerdasan matematis logis tinggi memperoleh prestasi belajar lebih baik daripada siswa yang memiliki kecerdasan rendah,serta siswa dengan kecerdasan matematis logissedang memperoleh prestasi belajar lebih baik daripada siswa dengan kecerdasan kecerdasan matematis logisrendah. (3) Pada masing-masing model pembelajaran, siswa yang memiliki kecerdasan matematis logis tinggi memperoleh prestasi belajar yang lebih baik dibandingkan dengan siswa yang memiliki kecerdasan matematis logis sedang,dan siswa dengan kecerdasan matematis logis tinggi 
memperoleh prestasi belajar lebih baik daripada siswa yang memiliki kecerdasan rendah,serta siswa dengan kecerdasan matematis logissedang memperoleh prestasi belajar lebih baik daripada siswa dengan kecerdasan matematis logisrendah. (4) Pada masing-masing kategori kecerdasan matematis logis, siswa yang dikenai model TSI-PS memperoleh prestasi belajar lebih baik daripada siswa yang dikenai model Klasikal-PS.

Berdasarkan kesimpulan hasil penelitian yang diperoleh maka peneliti dapat memberikan saran kepada guru agar menerapkan model TSI dengan pendekatan saintifik untuk meningkatkan prestasi belajar siswa.Selain itu, diharapkan guru dapat memahami karakteristik kecerdasan matematis logis yang dimiliki siswa sehingga dapat dipilih kegiatan pembelajaran yang dapat mengakomodir dan sesuai dengan karakteristik siswa. Peneliti juga menganjurkan bagi peneliti lain agar dapat diteliti kembali model pembelajaran kooperatif tipe TSI dengan pendekatan saintifik yang ditinjau dengan salah satu aspek kecerdasan multiple selain kecerdasan matematis logis.

\section{DAFTAR PUSTAKA}

Abdulkarim, R., \& Al Jadiry, A. (2012). The Effect of Using Cooperative Learning and Multiple Intelligence Theory on Physical Concepts Acquisition. British Journal of Arts and Social Sciences, 10( 11), 137-152.

Anggraheni, Vina Tri, (2013), "Penerapan Model Learning Cycle 7E untuk Meningkatkan Pemahaman dan Kreativitas Belajar Matematika Siswa Kelas VIII C SMP Negeri I Karangnyar Tahun Pelajaran 2012/2013”, Skripsi, UNS

Arra, C. T., D'Antonio, M. D. \& D'Antonio Jr. M .(2011). Students' Preferences for Cooperative Learning Instructional Approaches: Considerations for College Teachers. Journal of Research in Education, 21( 1), 114-126.

Armstrong, T. (2009).Multiple intelligences in the classrooom (3rd ed.). Alexandria: ASCD

Astan, F. M. \& Rahmita, Y. G. (2013). Penerapan Pendekatan Scientific Dalam Pembelajaran Matematika SMP Kelasi VII Materi Bilangan (Pecahan). Prosiding Seminar Nasional Matematika dan Pendidikan Matematika UNY: 9 November 2013.

Awofala, A. O. A., Fatade, O. A. \& Ola-Oluwa, A. S. (2012). Achievement in Cooperative versus Individualistic Goal-Structured Junior Secondary School Mathematics Classrooms in Nigeria. International Journal of Mathematics Trends and Technology, 3( 3), 7-12. 
Azmir, M., Mat Rahim, A. \& Sulaiman, A. (2011). Cooperative Learning Approach to Improve Soft-Skills Among University Students. Elixir Lead, Mgmt, 34(372), 2530-2534.

Betz, F. (2011).Managing Science: Innovation, Technology, and Knowledge Management 9.New York: Springer

Budiyono. (2013). Statistika Untuk Penelitian. Surakarta: UNS Press.

Farzaneh, N. \& Nejadesari, D. (2014). Students' Attitude Towards Using Cooperative Learning for Teaching and Reading Comprehension. Theory and Practice in Language Studies, 4(2), 287-292.

Hudoyo, H. (1988).Mengajar Belajar Matematika. Jakarta: dirjen DIKTI.

Huri Suhendri. (2012). Pengaruh Kecerdasan Matematis Logis, Rasa Percaya Diri, dan Kemandirian Belajar Terhadap Hasil Belajar Matematika. Prosiding Seminar Nasional Matematika dan Pendidikan Matematika UNY: November 2012

Igan Trisna Jayantika. (2013). Kontribusi Bakat Numerik , Kecerdasan Spasial, dan Kecerdasan Matematis Logis Terhadap Prestasi Belajar Matematika Siswa SD Negeri di Kabupaten Buleleng. E-Journal Program Pascasarjana Universitas Pendidikan Ganesha, 2, 1-11.

Johnson, J.(2000).Teaching and Learning Mathematics: Using Research to Shift From the "Yesterday" Mind to the "Tomorrow" Mind.Washington: State Superintendent of Public Instruction.

Johson, D. W., dan Johson, R. T. (2000). The Cooperative Learning Center at The University of Minnesota. Minnesota: University of Minnesota.

Kagan, S.\& Kagan, M. (1998).Multiple Intellingences: The Complete MI Book. San Cemente, CA: Kagan.

Lian, H. L.\& Idris, N. (2006).Assesing Algebraic Solving Ability of Form Four Students.International Electronic Journal of Mathematics Education.Vol. 1.No. $1.55-76$.

Liang, T. (2002).Implementing Cooperative Learning In EFL Theacing: Process and Effects. A Thesis For The Degree of Doctor of Philosophy, National Taiwan Normal University

Maharani, R. (2015). Eksperimentasi Model Pembelajaran kooperatif tipe Three Steps Interview (TSI) dan Tipe Think Pair Share (TPS) dengan Pendekatan Saintifik pada Materi Fungsi Ditinjau dari Multiple Intelligences Siswa Kelas VIII SMP Negeri Se-Kabupaten Sukoharjo Tahun Pelajaran 2014/2015. Thesis. Universitas Sebelas Maret Surakarta 
Maharani, R.,Aulia, F.N.N., Wahyuni, T.F., Lestari, M.(2016). Eksperimentasi Model Pembelajaran Kooperatif Tipe Think Pair Share (TPS) dengan Pendekatan Saintifik pada Materi Fungsi Ditinjau dari Multiple Intelligence Siswa Kelas VIII SMP Negeri 7 Sukoharjo Tahun Pelajaran 2015/2016. Proseeding Seminar Internasional and Call for Paper ICIES. 2(1). 852

Terwel, J. (2011). Cooperative Learning and Mathematics Education: A Happy Marriage?.The OECD/ France Workshop Paris: 23-24 May 2001.

The National Center on Quality Teaching and Learning (NCQTL). (2012). Learning Activity Using The Scientific Method. Planning in Your Classroom: Facilitator Guide. The National Center on Quality Teaching and Learning (NCQTL).

University on North Texas (UNT).(2008). Achieve Texas. Classroom Best Practices: Cooperative Learning. Texas Education Agency.

Zakaria, E., Chin, C.L. \& Daud, Y. (2010). The Effect of Cooperative Learning on Students' Mathematics Achievement and Attitude towards Mathematics. Journal of Social Sciences. Vol. 6. No. 2. 272-275. 